\title{
LAS081 1: From Combinatorial Chemistry to Activation of Antioxidant Response Element
}

\author{
Ming Zhu, ${ }^{1}$ Hyounggee Baek, ${ }^{1}$ Ruiwu Liu, ${ }^{1}$ Aimin Song, ${ }^{1}$ Kit Lam, ${ }^{1}$ and Derick Lau ${ }^{1,2}$ \\ ${ }^{1}$ Division of Hematology/Oncology, Department of Internal Medicine, UC-Davis Cancer Center, University of California-Davis, \\ 4501 X Street, Sacramento, CA 95817, USA \\ ${ }^{2}$ Department of Internal Medicine, Veteran Administration Northern California Health System, 4501 X Street, Sacramento, \\ CA 95817, USA
}

Correspondence should be addressed to Derick Lau, derick.lau@ucdmc.ucdavis.edu

Received 6 May 2009; Revised 1 July 2009; Accepted 7 July 2009

Recommended by Ayman El-Kadi

\begin{abstract}
The antioxidant response element (ARE) and its transcription factor, nuclear factor-erythroid 2 p45-related factor 2 (Nrf2), are potential targets for cancer chemoprevention. We sought to screen small molecules synthesized with combinatorial chemistry for activation of ARE. By high-throughput screening of 9400 small molecules from 10 combinatorial chemical libraries using HepG2 cells with an ARE-driven reporter, we have identified a novel small molecule, 1,2-dimethoxy-4,5-dinitrobenzene (LAS0811), as an activator of the ARE. LAS0811 upregulated the activity of $\mathrm{NAD}(\mathrm{P}) \mathrm{H}$ :quinone oxidoreductase 1 (NQO1), a representative antioxidative enzyme regulated by ARE. It enhanced production of an endogenous reducing agent, glutathione (GSH). In addition, LAS0811 induced expression of heme oxygenase 1 (HO1), which is an ARE-regulated enzyme with anti-inflammatory activity. Furthermore, LAS0811 reduced cell death due to the cytotoxic stress of a strong oxidant, t-butyl hydroperoxide (t-BOOH). Mechanistically, LAS0811 upregulated the expression of Nrf2 and promoted its translocation into the nuclei leading to subsequent ARE activation. Taken together, LAS0811 is a novel activator of the ARE and its associated detoxifying genes and, thus, a potential agent for cancer chemoprevention.
\end{abstract}

Copyright () 2009 Ming Zhu et al. This is an open access article distributed under the Creative Commons Attribution License, which permits unrestricted use, distribution, and reproduction in any medium, provided the original work is properly cited.

\section{Introduction}

Chemoprevention is a promising strategy to prevent cancer by employing small molecules to enhance production of phase II detoxifying enzymes which are capable of scavenging carcinogens [1]. A number of structurally unrelated molecules, such as anethole dithiolethiones, curcumin, isothiocyanates, caffeic acid, phenethyl esters, flavonoids, and triterpenoids, have been shown to activate ARE and subsequent induction of the phase II detoxifying enzymes $[2,3]$. The ARE was first discovered and named by Pickett and his colleagues [4]. A fuller characterization of the DNA consensus sequence required for ARE activity, including the requirement of $5^{\prime}$-flanking sequences, was subsequently reported by Wasserman and Fahl [5] and by Nioi et al. [6]. The ARE is a cis-acting element located in the promoter region of a number of genes encoding phase II detoxifying enzymes and antioxidative proteins $[7,8]$. These enzymes and proteins include $\mathrm{NAD}(\mathrm{P}) \mathrm{H}$ :quinone oxidoreductase 1 (NQO1), glutathione S-transferase (GST), $\gamma$-glutamatecysteine ligase (GCL), heme oxygenase 1 (HO1), thioredoxin reductase- 1 , and thioredoxin.

Activation of ARE is regulated by a transcription factor, Nrf2, a member of the Cap'n'Collar family of transcription factors that share a highly conserved basic leucine-zipper region [9]. It has been shown that Nrf2 is normally sequestered in the cytoplasm as an inactive complex with Kelch-like ECH-associated protein 1 (Keap1). In response to certain extracellular stimuli, Nrf2 dissociates from Keap1 and translocates into the nucleus, where Nrf2 heterodimerizes with a small Maf protein binds to the ARE and, subsequently, activates transcription of ARE-dependent genes [10]. However, other mechanisms of regulation of Nrf2, including stabilization of the Nrf2 protein by its inducers, have also been proposed and recently reviewed by Hayes and McMahon [11]. The Nrf2/ARE signaling pathway 
apparently plays an important role in cellular protection in response to oxidative stresses [12]. For example, Nrf2deficient mice are more susceptible than wild-type mice to oxidative injury and chemical-induced carcinogenesis [13]. Therefore, the Nrf2/ARE signaling pathway is a logical target for identifying novel chemopreventive agents [14, $15]$.

In the current study, we report the identification of a novel ARE activator, 1,2-dimethoxy-4,5-dinitrobenzene (LAS0811), by screening 10 combinatorial libraries of small molecules using an ARE-driven reporter assay.

\section{Material and Methods}

2.1. Chemicals and Reagents. t-Butylhydroquinone (tBHQ), reduced glutathione (GSH), dicumarol, flavin adenine dinucleotide (FAD), $\beta$-nicotinamide adenine dinucleotide phosphaste (NADP), glucose-6-phosphate, glucose-6-phosphate dehydrogenase, 3-(4,5-dimethylthiazol-2-yl)-2,5-diphenyltetrazolium bromide (MTT), menadione, metaphosphoric acid, and t-butyl hydroperoxide $(\mathrm{t}-\mathrm{BOOH})$ were purchased from Sigma Chemical Co. (St. Louis, MO); Dc Protein Assay kit from Bio-Rad Labs (Hercules, CA); and GSH-400 assay from Oxis International Inc. (Foster City, CA).

2.2. Combinatorial Libraries. Ten combinatorial chemical libraries, consisting of 9400 small molecules, were synthesized as a part of a combinatorial chemistry program in our institution. As shown in Figure 1, each library was generated from reactions of a basic chemical scaffold with different building blocks using methods as previously reported by us [16-22]. The purity of each compound was confirmed to be at least $98 \%$ as analyzed by high-pressure liquid chromatography. They were kept in dimethyl sulfoxide (DMSO) in 96-well plates.

2.3. Cell Cultures. A human hepatocellular carcinoma cell line, HepG2, was obtained from American Type Culture Collection (Rockville, MD). This cell line was maintained in Dulbecco's modified Eagle's medium (DMEM) (Invitrogen, Carlsbad, CA) supplemented with $10 \%$ fetal bovine serum, $100 \mathrm{U} / \mathrm{mL}$ of penicillin, and $100 \mathrm{U} / \mathrm{mL}$ of streptomycin (GibcoBRL, Grand Island, NY) in a humidified atmosphere of $5 \% \mathrm{CO}_{2}$ and $95 \%$ air at $37^{\circ} \mathrm{C}$.

2.4. In Vitro Model of ARE Activation. An in vitro model for regulation of ARE has been developed by stable transfection into the HepG2 cells, a reporter gene of green fluorescent protein (GFP) driven by four copies of ARE and a thymidine kinase (TK) promoter as previously described by us [23]. The expression of GFP was inducible in the HapG2 cells transfected only with the ARE/TK-GFP construct but not with the TK-GFP construct. Level of fluorescence emitted by GFP reflected degree of ARE activation. This assay has been validated by applying various well-known activators of ARE including tBHQ [24].
2.5. Screening of Chemical Libraries for ARE Activation. Each small molecule was diluted with DMEM, and the maximal concentration of DMSO in each assay was not to exceed $0.25 \%$. The HepG2 cells harboring the ARE/TK-GFP were seeded into wells $\left(4 \times 10^{4}\right.$ cells per well) of a 96-well plate and allowed to attach overnight. The cells were exposed to each test compound, at a concentration of $10 \mu \mathrm{M}$, for 24 hours, with $\mathrm{tBHQ}$ serving as a positive control. The medium was removed and $100 \mu \mathrm{L}$ of phosphate-buffered saline (PBS) was added to each well. Fluorescent intensity, which was an indicator of the level of GFP expression, was measured at the excitation/emission wavelengths of $485 / 530 \mathrm{~nm}$ using a fluorescent microplate reader. The relative density of live cells was determined using the MTT assay [25]. The fluorescent intensity of GFP was normalized to density of live cells in each well by dividing the fluorescent intensity to the absorbance, at $570 \mathrm{~nm}$, of the formazan dye formed from MTT by the live cells. Compounds, which showed enhancement of relative fluorescent intensity equal to or higher than $\mathrm{tBHQ}$, were selected for secondary screening at concentrations ranging from $0.1 \mu \mathrm{M}$ to $30 \mu \mathrm{M}$ in triplicates. Cytotoxicity of the lead compounds was also determined over a dose range of 0 to $100 \mu \mathrm{M}$ using the MTT assay.

2.6. Measurement of Down-Stream Markers of ARE Activation. To further confirm the activation of ARE by LAS0811, the following down-stream markers of ARE in the HepG2 cells were measured.

2.6.1. NQO1 Activity. HepG2 cells were exposed to 0 to $30 \mu \mathrm{M}$ of LAS0811 for 24 hours. Cellular NQO1 activity was quantified using a microtiter-plate-based spectroscopic assay [26]. Cell pellets were sonicated in $150 \mu \mathrm{L}$ of PBS and centrifuged at $12000 \mathrm{~g}$ at $4^{\circ} \mathrm{C}$ for 5 minutes. The supernatant fraction was diluted with $10 \mathrm{mM}$ Tris- $\mathrm{HCl}$ buffer, $\mathrm{pH}$ 7.4. To exclude nonspecific enzymatic activity, $50 \mu \mathrm{L}$ of the buffer containing $0.3 \mathrm{mM}$ of dicumarol was added to parallel wells in place of the regular buffer. Next, $200 \mu \mathrm{L}$ of an assay solution, containing Tris- $\mathrm{HCl}(25 \mathrm{mM}, \mathrm{pH} 7.4)$, bovine serum albumin (BSA) $(0.5 \%)$, Tween $20(0.025 \%)$, FAD $(5 \mu \mathrm{M})$, NADP $(30 \mu \mathrm{M})$, glucose-6-phosphate $(1 \mu \mathrm{M})$, glucose-6phosphate dehydrogenase $(2 \mathrm{U} / \mathrm{mL})$, MTT $(0.3 \mathrm{mg} / \mathrm{mL})$, and menadione $(25 \mu \mathrm{M})$, was added to each well. The reaction rate was immediately measured at $610 \mathrm{~nm}$ for 5 minutes using a microtiter plate reader.

2.6.2. GSH Level. HepG2 cells were exposed to 0 to $30 \mu \mathrm{M}$ of LAS0811 for 24 hours. Cellular GSH level was determined using a GSH-400 assay kit (Oxis International, Inc, Foster City, CA). Each cell pellet was resuspended and sonicated in 4 volumes of ice-cold 5\% metaphosphoric acid. The lysates were centrifuged at $10000 \mathrm{~g}$ at $4^{\circ} \mathrm{C}$ for 5 minutes. Each supernatant fraction $(\sim 30 \mu \mathrm{L})$ was mixed with $90 \mu \mathrm{L}$ of reaction buffer and $5 \mu \mathrm{L}$ of chromogenic reagent followed by $5 \mu \mathrm{L}$ of $30 \% \mathrm{NaOH}$. After incubation for 10 minutes, the absorbance at $400 \mathrm{~nm}$ was measured with a microtiter plate reader. A calibration curve of GSH was constructed using commercially available GSH. 
Library L-1<smiles>[R1]Nc1cc(O[R2])c([N+](=O)[O-])cc1[N+](=O)[O-]</smiles>

Library L-5<smiles>[R1]Sc1nc2cc3c(C)c(C(N)=O)c(=O)oc3cc2n1[R1]</smiles>

Library L-9<smiles>[X][X]c1cc([N+](=O)[O-])c([N+](=O)[O-])cc1O[R]</smiles>

Library L-2<smiles>[R2]c1nc2cc3c(C)c(C(N)=O)c(=O)oc3cc2n1[R]</smiles>

Library L-6<smiles>[R2]Nc1nc2cc3c(C)c(C(N)=O)c(=O)oc3cc2n1[R1]</smiles>

Library L-10<smiles>[R12]NC1CSc2cc3oc(=O)c(C(N)=O)c(C)c3cc2N([R1])C1=O</smiles>

Library L-3<smiles>[R]C1C(=O)N([R3])c2cc3c(C)c(C(N)=O)c(=O)oc3cc2N1[R1]</smiles>

Library L-7<smiles></smiles>

Library L-4<smiles>[R2]Nc1nc2cc(C(N)=O)ccc2n1[R1]</smiles>

FIGURE 1: General chemical structures of 10 combinatorial libraries of small molecules, which were screened with the HepG2/ARE-GFP cells. $R_{1}, R_{2}$, and $R_{3}$ are alkyl or aryl groups. LAS0811 was identified from library L-9.

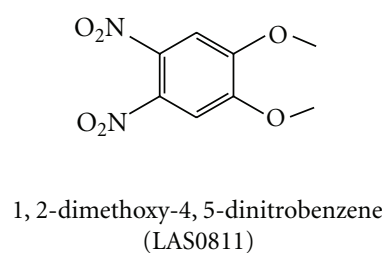

(LAS0811)

Figure 2: Chemical structures of LAS0811 and tBHQ.

2.6.3. HO1 Expression. HepG2 cells were exposed to LAS0811 at 0 to $50 \mu \mathrm{M}$ for 24 hours. Whole-cell lysates were prepared by suspending cell pellets in Cellytic M lysis reagent (Sigma, St. Louis, MO). After centrifugation at 10,000 g, supernatants were collected and protein concentrations were determined using the Dc Protein Assay kit (Bio-Rad). Equal amounts of lysate protein were analyzed on a 10\% SDSpolyacrylamine gel and transferred onto a nitrocellulose membrane. The membrane was probed with a rabbit antihuman HO1 primary antibody (Santa Cruz Biotechnology Inc, Santa Cruz, CA) followed by a goat-antirabbit secondary antibody conjugated with horseradish peroxidase. Detection was accomplished with the ECL reagents (Amersham Pharmacia Biotech, Piscataway, NJ). The relative level of expression of $\mathrm{HO} 1$ was determined by dividing the density of each band of $\mathrm{HO} 1$ to that of $\beta$-actin as detected by a densitometer.
2.7. Protection against $t-B O O H-I n d u c e d$ Cytotoxicity. tButyl hydroperoxide (t-BOOH) is a strong oxidant and highly cytotoxic. The antioxidative effect of LAS0811 was demonstrated by its potency of protecting HepG2 cells from the t-BOOH-induced cytotoxicity. HepG2 cells were plated in a 96-well plate $\left(4 \times 10^{4}\right.$ cells per well $)$. After incubating overnight, cells were pretreated with LAS0811 at concentrations of 0 to $100 \mu \mathrm{M}$ for 24 hours. The culture medium was replaced with fresh medium containing $1 \mathrm{mM}$ of $\mathrm{t}-\mathrm{BOOH}$ and the cells were incubated for an additional 10 hours. Cell cytotoxicity was measured with the MTT assay.

2.8. Upregulation and Translocation of Nrf2. To investigate if the activation of the ARE-dependent genes by LAS0811 was associated with a concomitant upregulation and nuclear translocation of $\mathrm{Nrf} 2$, we examined the appearance of the Nrf2 protein in cytoplasm and nuclei in the HepG2 cells following exposure to LAS0811. The HepG2 cells were grown on glass cover slides overnight, and exposed to LAS0811 at concentrations of 0 to $30 \mu \mathrm{M}$ for 3 and 18 hours. The cells were probed with a rabbit antihuman Nrf2 antibody (Santa Cruz Biotechnology, Inc. Santa Cruz) followed by a secondary swine antirabbit IgG conjugated with FITC. The nuclei were counter-stained with 4',6-diamidino-2phenylindole (DAPI). The glass slides were examined under a deconvolution fluorescent microscope. 

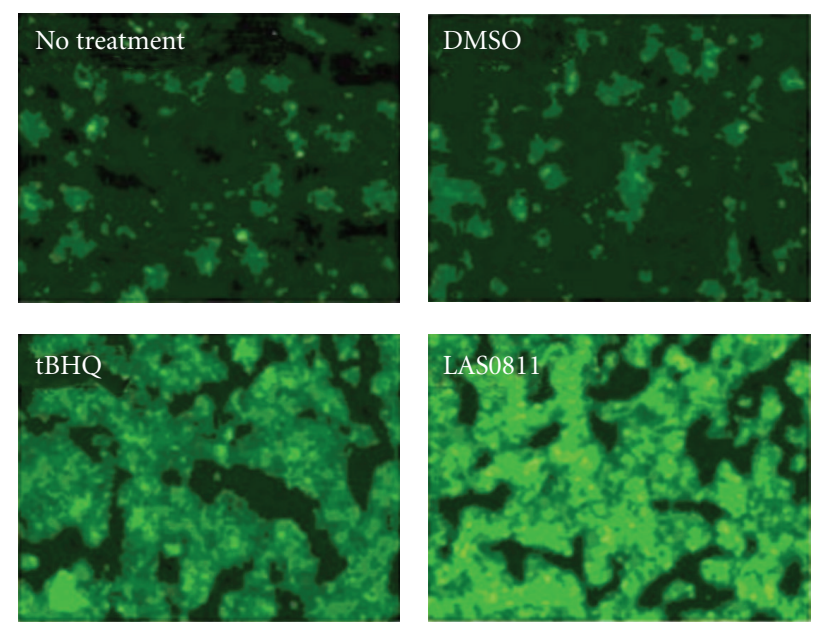

(a)

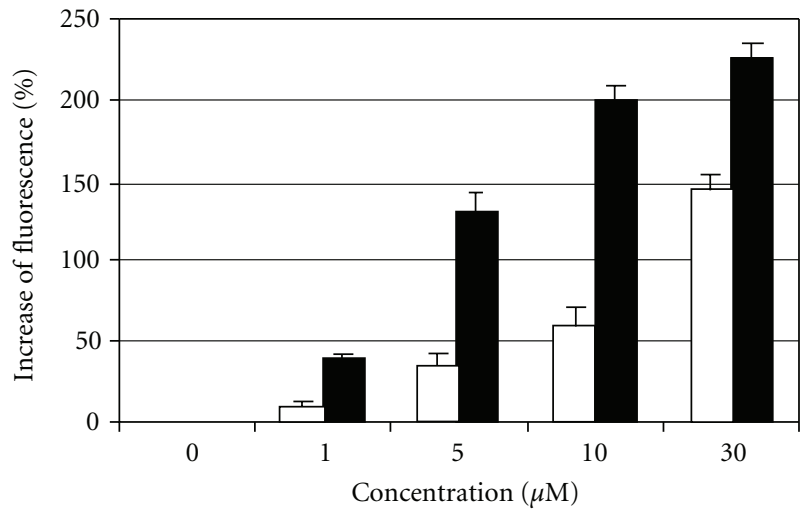

tBHQ

LAS0811

FIGURE 3: (a) Fluorescent images of the HepG2/ARE-GFP cells with no treatment or treatment with DMSO (0.5\%), LAS0811 (30 $\mu$ M, 24 hours), or tBHQ $(30 \mu \mathrm{M}, 24$ hours). Magnification $\times 100$. (b) Dose-dependent upregulation of expression of the fluorescent GFP after exposure of the HepG2/ARE-GFP cells to LAS0811 or tBHQ for 24 hours. Mean \pm SD, $n=3$.

2.9. Statistical Analysis. Each assay was performed at least 3 times. Results were expressed, where appropriate, as mean \pm standard deviation (SD). Student's $t$-test was used to determine statistically significant difference $(P<.05)$ between treatment groups.

\section{Results}

3.1. Screening of Combinatorial Libraries for ARE Activation. Upon screening 10 combinatorial chemical libraries consisting of 9400 small molecules (Figure 1), we have identified, from library L9, one novel compound, 1,2-dimethoxy-4,5dinitrobenzene (LAS0811), which consistently induced ARE activation higher than the prototype activator of ARE, tBHQ. Many analogs of each library weakly activated ARE (i.e., the enhancement of fluorescence was less than $50 \%$ of that induced by tBHQ). There was no known AREactivator within each library. The structures of LAS0811 and tBHQ are shown in Figure 2. LAS0811 and tBHQ were not autofluorescent. The HepG2 cells harboring the ARE/TK-GFP expressed a low basal level of fluorescence. Upon exposure of the cells to tBHQ or LAS0811 over 24 hours, the GFP expression was enhanced as shown in Figure 3(a). The induction of GFP expression by either $\mathrm{tBHQ}$ or LAS0811 was dose-dependent as shown in Figure 3(b). LAS0811 induced GFP expression significantly higher than tBHQ over the concentration range of 1 to $30 \mu \mathrm{M}$. LAS 0811 induced GFP expression by $130 \%$ and $225 \%$ over the baseline at $5 \mu \mathrm{M}$ and $30 \mu \mathrm{M}$, respectively. The level of GFP expression induced by LAS0811 was significantly higher than that induced by $\operatorname{tBHQ}(P<.05)$. Of note, the LAS0811 was not cytotoxic to the HepG2 cells over the concentration range of 0 to $50 \mu \mathrm{M}$ as determined by the MTT assay. At $100 \mu \mathrm{M}$, the viability of HepG2 cells was $90 \%$.
3.2. Induction of NQO1 Activity, GSH and HO1 Expressions. After exposure of the HepG2 cells to LAS0811 for 24 hours, the NQO1 activity was increased in a dose-dependent manner as shown in Figure 4(a). The NQO1 activity was increased significantly by $20 \%, 52 \%$, and $100 \%$ with 5,10 , and $30 \mu \mathrm{M}$ of LAS0811, respectively. Similarly, the GSH levels were significantly increased by $25 \%, 54 \%$, and $143 \%$ with 5,10 , and $30 \mu \mathrm{M}$ of LAS0811, respectively, as shown in Figure 4(b). LAS0811, at concentrations of 10 and $50 \mu \mathrm{M}$, significantly upregulated the expression of the $\mathrm{HO} 1$ protein by 2 - and 4-fold, respectively, of the HepG2 cells as shown in Figure 5.

3.3. Protection of $t-B O O H-I n d u c e d$ Cytotoxicity. Pretreatment with LAS0811 significantly protected HepG2 cells against t-BOOH-induced oxidative cytotoxicity. At a concentration of $1 \mathrm{mM}$, t-BOOH reduced viability of the HepG2 cells to $16 \%$ of the control. Preexposure of the cells to LAS0811 for 24 hours significantly increased cell viability to $50 \%$ at $5 \mu \mathrm{M}$ and $72 \%$ at $30 \mu \mathrm{M}$ as shown in Figure 6 .

3.4. Upregulation and Translocation of Nrf2. The time course of appearance of $\mathrm{Nrf} 2$, as detected with fluorescent microscopy, in the cytoplasm and nuclei of the HepG2 cells in response to LAS0811 exposure is shown in Figure 7. Enhancement of Nrf2 expression was detected in the cytoplasm 3 hours after exposure to $30 \mu \mathrm{M}$ of LAS0811. By 18 hours, the Nrf2 protein was noticeably located in the nuclei as well as in the cytoplasm. These results indicated that LAS0811 upregulated the expression of Nrf2 in the cytoplasm and promoted its subsequent translocation from the cytoplasm into the nuclei. 


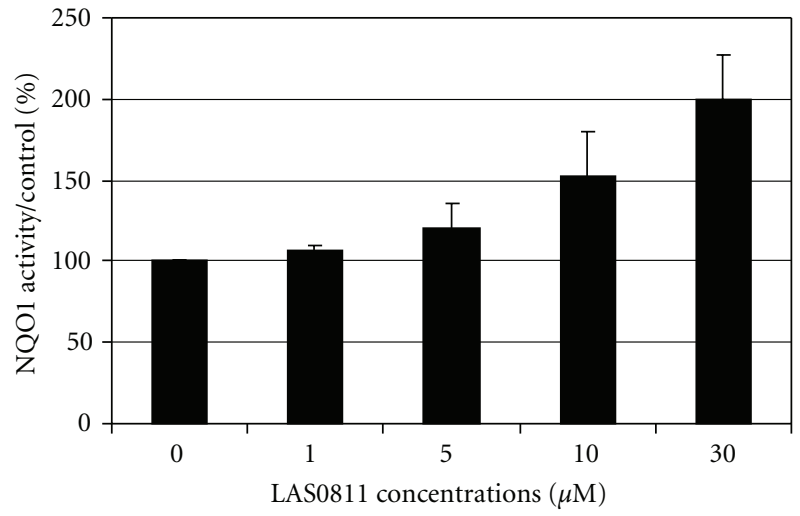

(a)

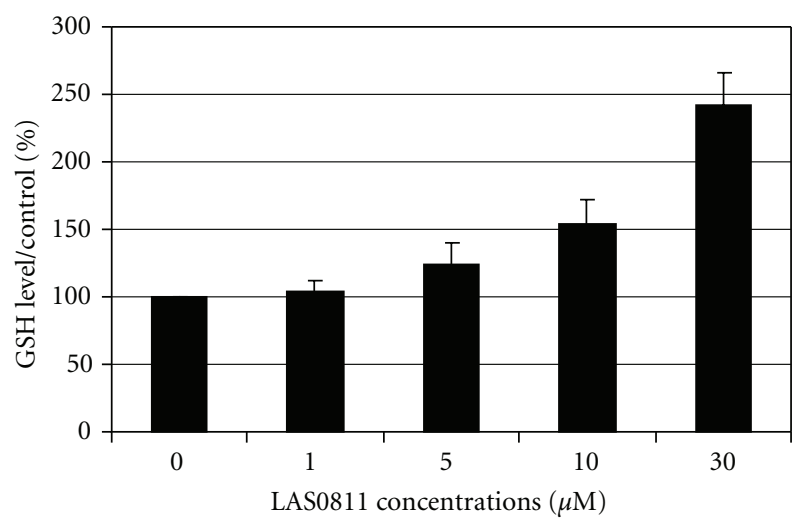

(b)

FIGURE 4: Dose-dependent increase of (a) NQO1 activity; (b) GSH level, after exposure of the HepG2 cells to LAS0811 at 1 to $30 \mu \mathrm{M}$ for 24 hours. Mean \pm SD, $n=3$.
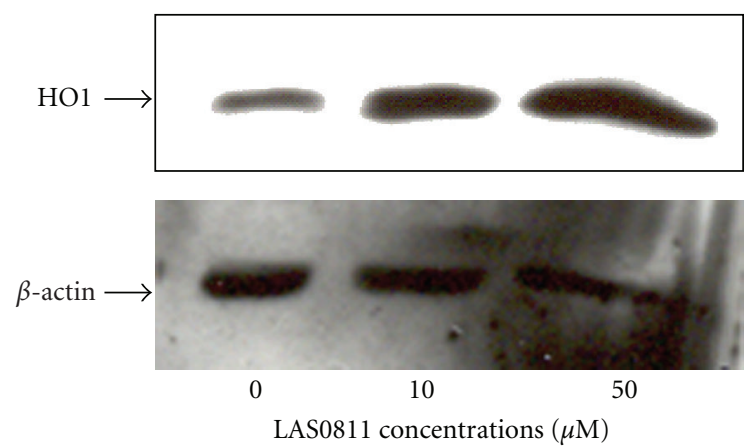

FIgURE 5: Effect of LAS0811 on HO1 expression in HepG2 cells: Dose-dependent response to LAS0811 at 0,10 , and $50 \mu \mathrm{M}$ for 24 hours.

\section{Discussion}

Induction of the Nrf2/ARE-regulated proteins, which detoxify potential carcinogens and oxidants, represents a promising strategy for cancer prevention. In this regard, many potential chemopreventive agents with a variety of chemical structures have been identified [2, 3]. However, clinical application of these agents has been hampered by their

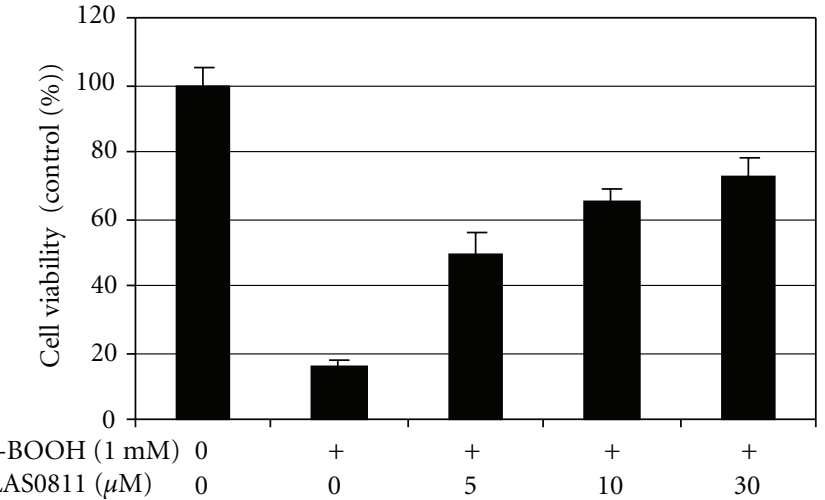

FIgURE 6: Dose-dependent enhancement of cell viability by LAS0811 of the HepG2 cells exposed to a cytotoxic oxidant, $t$ $\mathrm{BOOH}$. HepG2 cells were pretreated with LAS0811 at 0 to $30 \mu \mathrm{M}$ for 24 hours followed by exposure to $1 \mathrm{mM}$ of t-BOOH for 10 hours. Mean $\pm \mathrm{SD}, n=3$.

toxicity or ineffectiveness in human subjects [27]. Therefore, the effort for searching of safe and effective chemopreventive agents continues.

Combinatorial chemistry is a powerful technology in simultaneously generating thousands of unique chemical entities [28]. We have generated 10 combinatorial chemical libraries of 9400 unique small molecules. Together with a high-throughput cell-based ARE functional assay, we have screened these libraries and identified a novel small molecule, LAS0811, which activates the Nrf2/ARE signaling pathway. LAS0811, at $30 \mu \mathrm{M}$, enhanced expression of the GFP protein by more than $200 \%$ with the cell-based model of GFP, yet the induction of expression or activity of GSH, HO1, and NQO1 varied from $100 \%$ to $200 \%$. The degree of upregulation of the different down-stream proteins was not identical as their regulatory mechanisms along the Nrf2/ARE axis may vary. We do not know if the metabolites of LAS0811 are biologically active as LAS0811 may be subjected to Odemethylation. Nevertheless, we have demonstrated that LAS0811 itself is an activator of ARE in all the in vitro assays conducted to date.

Firstly, LAS0811 protects cells from cytotoxicity of a strong oxidant, t-BOOH. We speculate that this protective effect is attributed, at least in part, to enhancement of expression and activity of the Nrf2/ARE-regulated cytoprotective genes as recently reported by Higgins et al. for sulforaphane [29]. Pretreatment of Nrf2+/+ mouse embryonic fibroblasts (MEFs) for 24 hours with an inducing dose of sulforaphane conferred 1.6-fold resistance against t-BOOH. In contrast, Nrf2-/- MEFs were 3-times more sensitive to t-BOOH than Nrf2+/+ MEFs and could not be protected against the peroxide by pretreatment with sulforaphane. In the current study, we have shown that LAS0811 enhanced the activity of NQO1 and increased the level of GSH. NQO1 plays an important role in protecting cells against ROS and maintaining genomic stability [30]. This enzyme metabolizes highly toxic and reactive quinone species, maintains redox homeostasis, and stabilizes the half-life of a tumor suppressor 


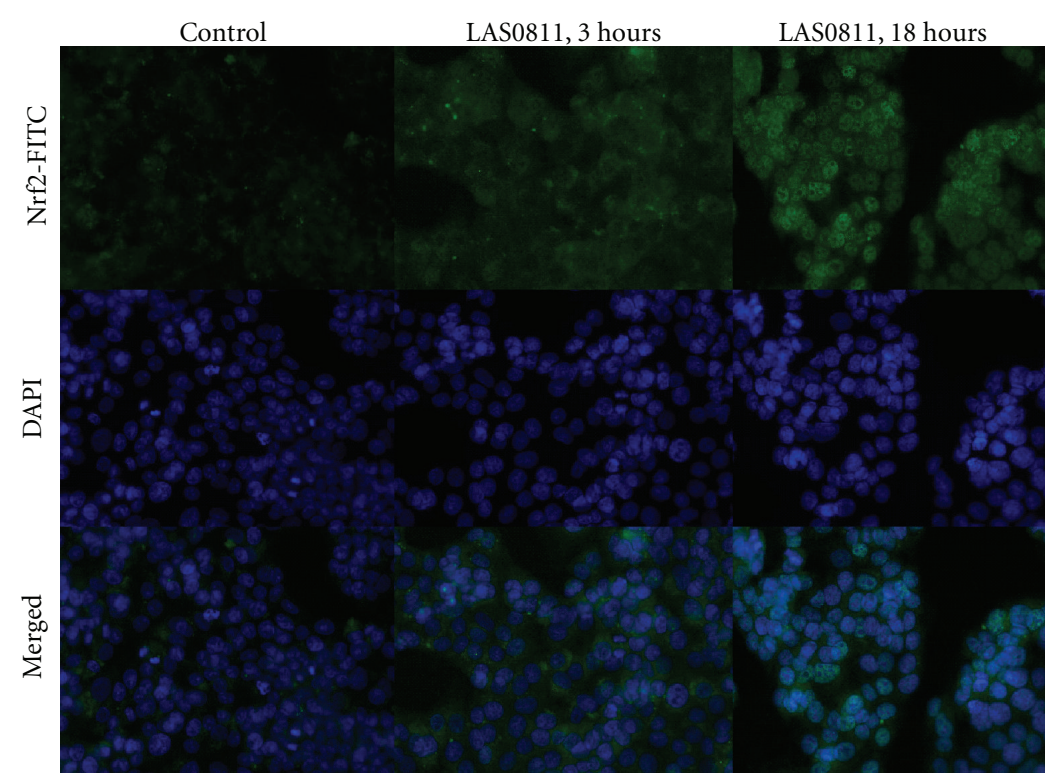

FIGURE 7: Fluorescent microscopy of Nrf2 expression in the cytoplasm and nuclei of HepG2 cells treated with $30 \mu \mathrm{M}$ of LAS0811 for 0, 3 , and 18 hours. DAPI was used to identify the nuclei. Magnification $\times 200$.

protein, p53 [31]. On the other hand, GSH is the most abundant reducing thiol in mammalian cells. It plays an important role in detoxifying ROS and serves as a cofactor for several peroxidases [32]. Intracellularly, GSH is synthesized consecutively by GCL and glutathione synthase. The ratelimiting GCL is regulated via the ARE signaling pathway [33].

Secondly, LAS0811 upregulates the expression of the enzyme, HO1, which possesses antioxidative, antiinflammatory and antiapoptotic activity $[34,35]$. It is the rate-limiting enzyme in the conversion of heme into biliverdin, carbon monoxide and free iron. The free heme moiety is a potentially toxic pro-oxidant. Biliverdin is very rapidly converted to bilirubin by the enzyme biliverdin reductase. Bilirubin is an antioxidant capable of scavenging peroxy radicals and inhibiting lipid peroxidation [36]. Carbon monoxide is also believed to play a role as a signaling molecule in the antiinflammatory and antiapoptotic pathways [37]. The expression of the $\mathrm{HO} 1$ gene is regulated mainly through the Nrf2/ARE pathway as it contains multiple copies of ARE sequences in its promoter [38]. It has also been shown that the expression of $\mathrm{HO} 1 \mathrm{can}$ be induced through other signaling pathways, such as MAPKs and PI3K-dependent Akt $[39,40]$. Whether these signaling pathways are involved in the LAS08111-mediated induction of HO1 remains to be delineated.

Lastly, LAS0811 enhances expression of Nrf2 in the cytoplasm and promotes its translocation into the nuclei. In concurrence with other investigators concerning the role of Nrf2, LAS0811 enhances expression of Nrf2 in the cytoplasm followed by its subsequent translocation into the nuclei in the HepG2 cells. In addition to the HepG2 cells, we have also observed similar phenomenon in an immortalized human bronchioepithelial cell line, HBE, and an immortalized mouse hippocampal cell line, HT22 (data not shown). We propose two possible mechanisms involved in the upregulation of Nrf2. First, the LAS0811 may act directly on ARE and induce Nrf2 expression based on the observation that expression of Nrf2 itself is regulated via ARE [41]. Second, LAS0811 may interrupt the binding of Nrf2 with Keap1 which binds and keeps Nrf1 in the cytoplasm. Dissociation of Nrf2 from Keap1 results in the availability of free Nrf2 and its subsequent translocation into the nuclei.

In summary, we have identified a novel small molecule, LAS0811, which activates the ARE/Nrf2 pathway. LAS0811 is being investigated as a chemopreventive agent in animal models.

\section{Abbreviations}

ARE: Antioxidant response element

BSA: Bovine serum albumin

DMEM: Dulbecco's Modified Eagle's medium

DMSO: Dimethyl sulfoxide

GFP: Green fluorescent protein

GSH: $\quad \gamma$-L-glutamyl-L-cysteinyl-glycine or glutathione

GCL: $\quad \gamma$-glutamate-cysteine ligase

HO1: Heme oxygenase-1

Keap1: $\quad$ Kelch-like ECH-associated protein 1

MTT: 3-(4,5-dimethylthiazol-2-yl)-2,5-diphenyl tetrazolium bromide

NO: $\quad$ Nitric oxide

NQO1: $\quad \mathrm{NAD}(\mathrm{P}) \mathrm{H}$ :quinone oxidoreductase 1

Nrf2: $\quad$ Nuclear factor erythroid2-related factor

PBS: $\quad$ Phosphate-buffered saline

tBHQ: t-butylhydroquinone

t-BOOH: t-butyl hydroperoxide. 


\section{Acknowledgment}

This work is supported in part by the UC Davis Clinical and Translational Science Center Grant no. UL1 RR024146 from the National Center for Research Resources (NCRR), NIH.

\section{References}

[1] M. B. Sporn and K. T. Liby, "Cancer chemoprevention: scientific promise, clinical uncertainty," Nature Clinical Practice Oncology, vol. 2, no. 10, pp. 518-525, 2005.

[2] J.-S. Lee and Y.-J. Surh, "Nrf2 as a novel molecular target for chemoprevention," Cancer Letters, vol. 224, no. 2, pp. 171-184, 2005.

[3] M. S. Yates, M. Tauchi, F. Katsuoka, et al., "Pharmacodynamic characterization of chemopreventive triterpenoids as exceptionally potent inducers of Nrf2-regulated genes," Molecular Cancer Therapeutics, vol. 6, no. 1, pp. 154-162, 2007.

[4] T. H. Rushmore, M. R. Morton, and C. B. Pickett, "The antioxidant responsive element: activation by oxidative stress and identification of the DNA consensus sequence required for functional activity," Journal of Biological Chemistry, vol. 266, no. 18, pp. 11632-11639, 1991.

[5] W. W. Wasserman and W. E. Fahl, "Functional antioxidant responsive elements," Proceedings of the National Academy of Sciences of the United States of America, vol. 94, no. 10, pp. 5361-5366, 1997.

[6] P. Nioi, M. McMahon, K. Itoh, M. Yamamoto, and J. D. Hayes, "Identification of a novel NRF2-regulated antioxidant response element (ARE) in the mouse $\operatorname{NAD}(\mathrm{P}) \mathrm{H}$ :quinone oxidoreductase 1 gene: reassessment of the ARE consensus sequence," Biochemical Journal, vol. 374, no. 2, pp. 337-348, 2003.

[7] W.-S. Jeong, M. Jun, and A.-N. T. Kong, "Nrf2: a potential molecular target for cancer chemoprevention by natural compounds," Antioxidants and Redox Signaling, vol. 8, no. 1-2, pp. 99-106, 2006.

[8] M.-K. Kwak, N. Wakabayashi, and T. W. Kensler, "Chemoprevention through the Keap1-Nrf2 signaling pathway by phase 2 enzyme inducers," Mutation Research, vol. 555, no. 1-2, pp. 133-148, 2004.

[9] T. Nguyen, P. J. Sherratt, and C. B. Pickett, "Regulatorymechanisms controlling gene expression mediated by the antioxidant response element," Annual Review of Pharmacology and Toxicology, vol. 43, pp. 233-260, 2003.

[10] M. Kobayashi and M. Yamamoto, "Molecular mechanisms activating the Nrf2-Keap1 pathway of antioxidant gene regulation," Antioxidants and Redox Signaling, vol. 7, no. 3-4, pp. 385-394, 2005.

[11] J. D. Hayes and M. McMahon, "NRF2 and KEAP1 mutations: permanent activation of an adaptive response in cancer," Trends in Biochemical Sciences, vol. 34, no. 4, pp. 176-188, 2009.

[12] H. Motohashi and M. Yamamoto, "Nrf2-Keap1 defines a physiologically important stress response mechanism," Trends in Molecular Medicine, vol. 10, no. 11, pp. 549-557, 2004.

[13] K. Iida, K. Itoh, Y. Kumagai, et al., "Nrf2 is essential for the chemopreventive efficacy of oltipraz against urinary bladder carcinogenesis," Cancer Research, vol. 64, no. 18, pp. 64246431, 2004.

[14] X. Yu and T. Kensler, "Nrf2 as a target for cancer chemoprevention," Mutation Research, vol. 591, no. 1-2, pp. 93-102, 2005.
[15] J.-S. Lee and Y.-J. Surh, "Nrf2 as a novel molecular target for chemoprevention," Cancer Letters, vol. 224, no. 2, pp. 171-184, 2005.

[16] S. R. Nagy, G. Liu, K. S. Lam, and M. S. Denison, "Identification of novel Ah receptor agonists using a high-throughput green fluorescent protein-based recombinant cell bioassay," Biochemistry, vol. 41, no. 3, pp. 861-868, 2002.

[17] A. Song, X. Wang, and K. S. Lam, "A convenient synthesis of coumarin-3-carboxylic acids via Knoevenagel condensation of Meldrum's acid with ortho-hydroxyaryl aldehydes or ketones," Tetrahedron Letters, vol. 44, no. 9, pp. 1755-1758, 2003.

[18] A. Song, J. Zhang, and K. S. Lam, "Synthesis and Reactions of 7-Fluoro-4-methyl-6-nitro-2-oxo-2H-1-benzopyran3-carboxylic acid: a novel scaffold for combinatorial synthesis of coumarins," Journal of Combinatorial Chemistry, vol. 6, no. 1, pp. 112-120, 2004.

[19] A. Song, J. Zhang, C. B. Lebrilla, and K. S. Lam, "Solidphase synthesis and spectral properties of 2-alkylthio$6 H$-pyrano[2,3- $f$ ]benzimidazole-6-ones: a combinatorial approach for 2-alkylthioimidazocoumarins," Journal of Combinatorial Chemistry, vol. 6, no. 4, pp. 604-610, 2004.

[20] A. Song and K. S. Lam, "Parallel solid-phase synthesis of 2arylamino-6H-pyrano[2,3- $f]$ benzimidazole-6-ones," Tetrahedron, vol. 60, no. 39, pp. 8605-8612, 2004.

[21] A. Song, J. Mařík, and K. S. Lam, "Solid-phase synthesis of 3-alkyl-2-arylamino-3,4-dihydroquinazolines," Tetrahedron Letters, vol. 45, no. 13, pp. 2727-2730, 2004.

[22] A. Song, L. Wu, L. Ho, and K. S. Lam, "Facile solid-phase synthesis of 2,3-disubstituted $6 H$-pyrano[2,3- $f$ ]benzimidazole6-ones," Tetrahedron, vol. 62, no. 18, pp. 4393-4399, 2006.

[23] M. Zhu and W. E. Fahl, "Development of a green fluorescent protein microplate assay for the screening of chemopreventive agents," Analytical Biochemistry, vol. 287, no. 2, pp. 210-217, 2000.

[24] R. Yu, T.-H. Tan, and A.-N. T. Kong, "Butylated hydroxyanisole and its metabolite tert-butylhydroquinone differentially regulate mitogen-activated protein kinases: the role of oxidative stress in the activation of mitogen-activated protein kinases by phenolic antioxidants," Journal of Biological Chemistry, vol. 272, no. 46, pp. 28962-28970, 1997.

[25] T. Mosmann, "Rapid colorimetric assay for cellular growth and survival: application to proliferation and cytotoxicity assays," Journal of Immunological Methods, vol. 65, no. 1-2, pp. 55-63, 1983.

[26] G. H. Posner, C.-G. Cho, J. V. Green, Y. Zhang, and P. Talalay, "Design and synthesis of bifunctional isothiocyanate analogs of sulforaphane: correlation between structure and potency as inducers of anticarcinogenic detoxication enzymes," Journal of Medicinal Chemistry, vol. 37, no. 1, pp. 170-176, 1994.

[27] L. Pendyala, G. Schwartz, W. Bolanowska-Higdon, et al., "Phase I/pharmacodynamic study of N-acetylcysteine/oltipraz in smokers: early termination due to excessive toxicity," Cancer Epidemiology Biomarkers and Prevention, vol. 10, no. 3, pp. 269-272, 2001.

[28] R. Liu, C.-Y. Hsieh, and K. S. Lam, "New approaches in identifying drugs to inactivate oncogene products," Seminars in Cancer Biology, vol. 14, no. 1, pp. 13-21, 2004.

[29] L. G. Higgins, M. O. Kelleher, I. M. Eggleston, K. Itoh, M. Yamamoto, and J. D. Hayes, "Transcription factor Nrf2 mediates an adaptive response to sulforaphane that protects fibroblasts in vitro against the cytotoxic effects of electrophiles, peroxides and redox-cycling agents," Toxicology and Applied Pharmacology, vol. 237, no. 3, pp. 267-280, 2009. 
[30] A. K. Jaiswal, "Regulation of genes encoding $\mathrm{NAD}(\mathrm{P}) \mathrm{H}$ : quinone oxidoreductases," Free Radical Biology and Medicine, vol. 29, no. 3-4, pp. 254-262, 2000.

[31] G. Asher, J. Lotem, R. Kama, L. Sachs, and Y. Shaul, "NQO1 stabilizes p53 through a distinct pathway," Proceedings of the National Academy of Sciences of the United States of America, vol. 99, no. 5, pp. 3099-3104, 2002.

[32] I. Rahman and W. MacNee, "Regulation of redox glutathione levels and gene transcription in lung inflammation: therapeutic approaches," Free Radical Biology and Medicine, vol. 28, no. 9, pp. 1405-1420, 2000.

[33] A. C. Wild, H. R. Moinova, and R. T. Mulcahy, "Regulation of $\gamma$-glutamylcysteine synthetase subunit gene expression by the transcription factor Nrf2," Journal of Biological Chemistry, vol. 274, no. 47, pp. 33627-33636, 1999.

[34] D. Willis, A. R. Moore, R. Frederick, and D. A. Willoughby, "Heme oxygenase: a novel target for the modulation of the inflammatory response," Nature Medicine, vol. 2, no. 1, pp. 8790, 1996.

[35] A. Prawan, J. K. Kundu, and Y.-J. Surh, "Molecular basis of heme oxygenase-1 induction: implications for chemoprevention and chemoprotection," Antioxidants and Redox Signaling, vol. 7, no. 11-12, pp. 1688-1703, 2005.

[36] K. K. Elbirt and H. L. Bonkovsky, "Heme oxygenase: recent advances in understanding its regulation and role," Proceedings of the Association of American Physicians, vol. 111, no. 5, pp. 438-447, 1999.

[37] H. P. Kim, S. W. Ryter, and A. M. K. Choi, "CO as a cellular signaling molecule," Annual Review of Pharmacology and Toxicology, vol. 46, pp. 411-449, 2006.

[38] J. Alam, D. Stewart, C. Touchard, S. Boinapally, A. M. K. Choi, and J. L. Cook, "Nrf2, a Cap'n'Collar transcription factor, regulates induction of the heme oxygenase-1 gene," Journal of Biological Chemistry, vol. 274, no. 37, pp. 26071-26078, 1999.

[39] T. Kietzmann, A. Samoylenko, and S. Immenschuh, "Transcriptional regulation of heme oxygenase-1 gene expression by MAP kinases of the JNK and p38 pathways in primary cultures of rat hepatocytes," Journal of Biological Chemistry, vol. 278, no. 20, pp. 17927-17936, 2003.

[40] D. Martin, A. I. Rojo, M. Salinas, et al., "Regulation of heme oxygenase-1 expression through the phosphatidylinositol 3kinase/Akt pathway and the Nrf2 transcription factor in response to the antioxidant phytochemical carnosol," Journal of Biological Chemistry, vol. 279, no. 10, pp. 8919-8929, 2004.

[41] M.-K. Kwak, K. Itoh, M. Yamamoto, and T. W. Kensler, "Enhanced expression of the transcription factor Nrf2 by cancer chemopreventive agents: role of antioxidant response element-like sequences in the nrf2 promoter," Molecular and Cellular Biology, vol. 22, no. 9, pp. 2883-2892, 2002. 

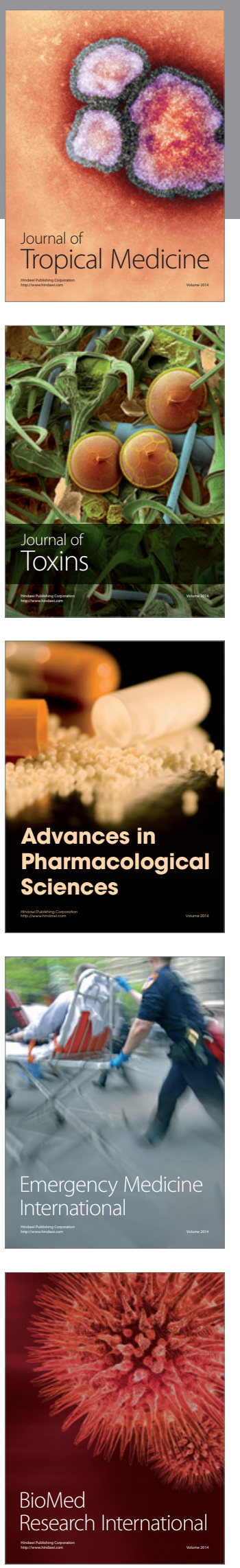
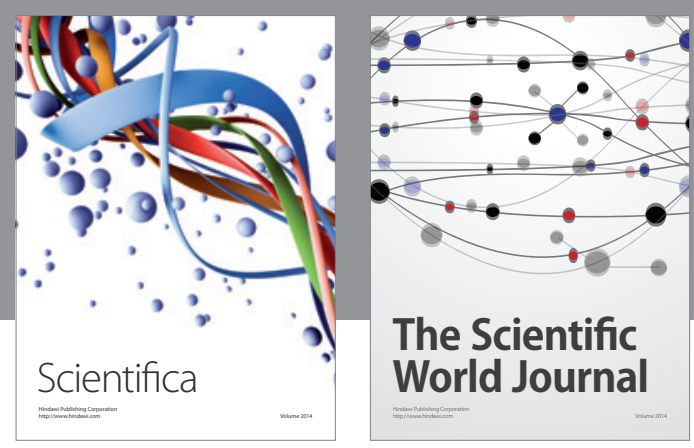

The Scientific World Journal
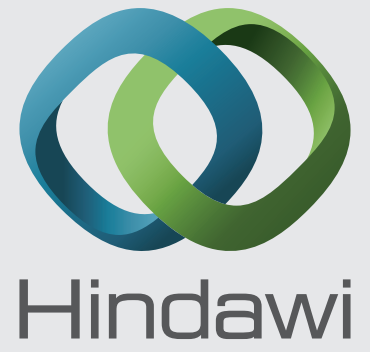

Submit your manuscripts at

http://www.hindawi.com
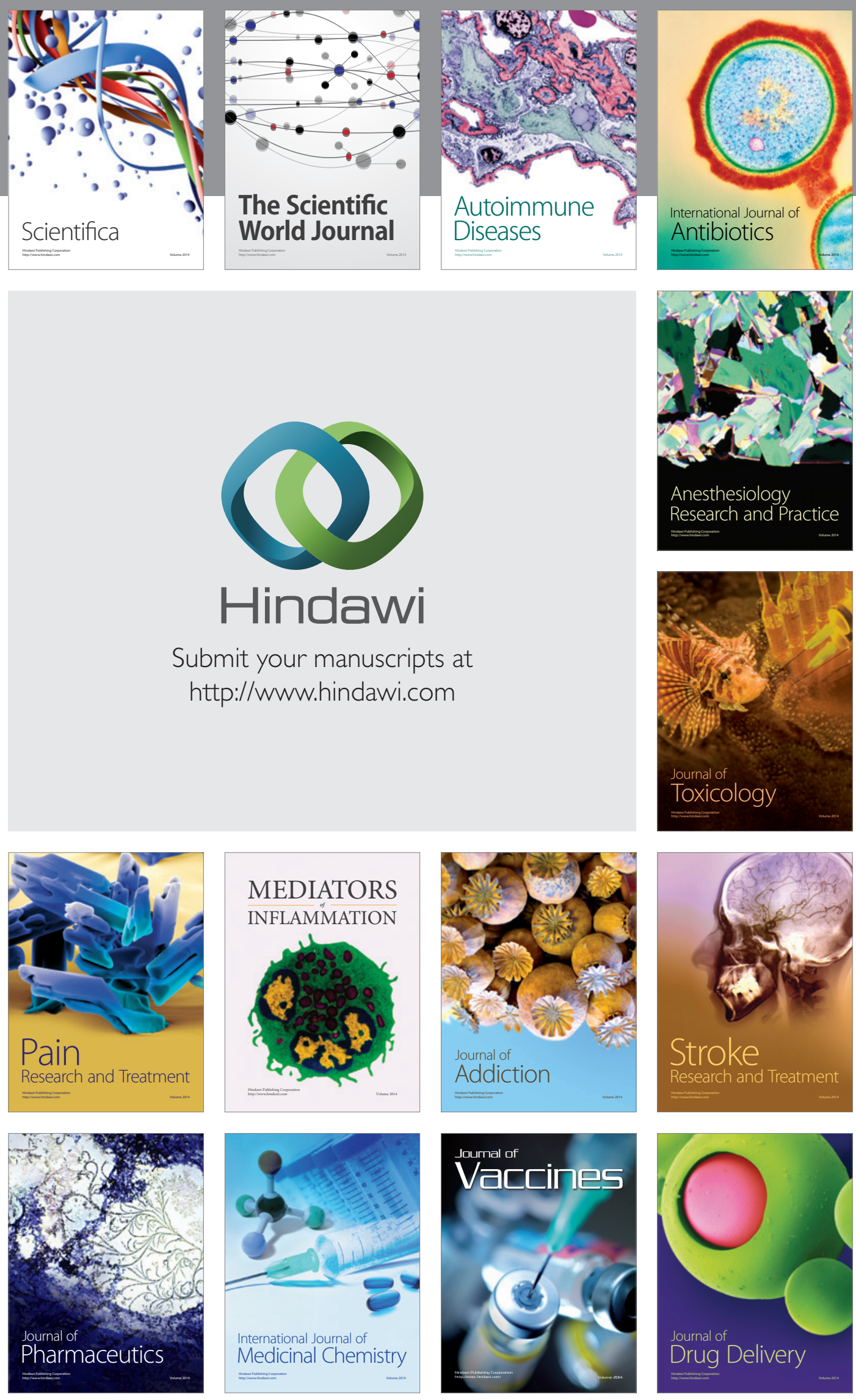